\title{
Female Discrimination in the Workplace: Skilled Communicators but Undermined Leaders
}

\author{
Allison Yue ${ }^{1}$ and Christine King ${ }^{1}$ \\ ${ }^{1}$ University High School, Los Angeles, CA, USA
}

\section{$\underline{\text { ABSTRACT }}$}

This literature review examines several studies related to differences in gender communication, gender perception, and the impact of workplace discrimination. Experimental studies on gender have revealed that women's communication style is seen as genteel and empathetic while men's communication styles are viewed as noisy and aggressive. And yet, people view leadership qualities as inherently more masculine than feminine. These differences are also reflected in leadership styles between men and women. The question remains if women display capable communication skills and leadership, why do discriminatory practices pervade in the workplace? Through a qualitative analysis of each paper, we draw the relationship between gender perceptions and workplace discrimination, including the lack of women in executive positions. A comparison between review articles helped to illustrate the differences in approach and similarity in results of pair of studies. Social theories presented in articles help to explain social phenomenon that undermine women. Concepts such as counter-stereotypical characteristics of women are discussed and the need for institutional policy enforcements is emphasized.

\section{Introduction}

In the United States, although women make up a significant number of the workforce, many key laws that protect women date back to the nineties. The Supreme Court case Harris v. Forklift Systems, Inc. (1993) made gender harassment illegal which includes discriminating between genders during the hiring process. In addition, it was only in 1998 that the Supreme Court stated that gender harassment falls under Title VII, a law banning sexual harassment. The percentage of women in the workplace has reached an all-time high overall; as of $2017,47 \%$ of the workplace was female in the United States but only about $7.7 \%$ of top executives are female. This disparity is the result of multiple factors, primarily stemming from the idea of an "old boys' club" at the top of the executive ladder (Hollis, 2017; Seo et al., 2017). This literature review paper will compare and contrast the current literature with its preceding research analyzing women's communication traits, stereotypical perceptions, and institutional discrimination in the workplace in the last 30 years.

\section{Background \& Definition}

Women and men are inherently different in their communication styles. Societal expectations and cultural norms play a large role in shaping stereotypes throughout history. With modernization of society, women were given more opportunities to join the workforce, often undermined in male-dominated workplaces. To protect the rights of minorities in professional settings, the Civil Rights Act of 1964 was a monumental law in the fight against discriminatory practices on people based on race, religion, sex, and national origin. Although gender-based discrimination was included in this act, the law often minimized cases of sexual harassment as inconsequential. For years, the Supreme Court stated that unwanted sexual advances in the workplace does not impact work productivity, therefore, it has no place in court (Crenshaw, 1995). Quid pro quo sexual harassment, which occurs when an employee faces unwanted sexual advances 
by an employer as a condition of employment, was not taken seriously even when women continued to report accounts of sexual harassment in the workplace. It wasn't until Williams vs. Saxbe in 1974, when Diane Williams reported her supervisor, who worked at the U.S. Justice Department, that quid pro quo harassment was considered to be a form of sex-based discrimination (Crenshaw, 1995).

Sex-based discrimination, however, is not always defined by sexual harassment, but rather, the lack of equal opportunity in the workplace, such as not being promoted based on gender, can limit a women's ability to succeed. Women are often snubbed of promotions or deemed incompetent without a fair review. Traits that "define" a leader are more commonly associated with men, whereas women who display such traits are seen as too aggressive and difficult to work with. The communication style of women, who are considered more empathetic while men are more forthright and direct, can further perpetuate the idea that women do not possess the characteristics of a strong leader.

\section{Literature Review}

\section{Communication Differences}

\section{Briton and Hall}

Gender analysis specific to workplace communication is a topic with limited research. Therefore, the two communication studies were selected strictly based on a comparison between two genders' (male and female) overall approach to communication. The first research was performed by Briton and Hall in 1995. For the study, a group of students from Northeastern University's psychology class -- 183 women, 258 men -- were asked to rank 20 behavioral traits in respect to gender. An example of verbal traits includes "talks a lot in mixed-sex groups" and "speaks loudly". On the other hand, an example of nonverbal traits includes "smiles a lot" and "has an expressive voice". The variance between the gender of participant and gender of target of observation were analyzed (Briton and Hall, 1995).

For verbal communication, the questionnaire analysis revealed that women were perceived as good listeners while the men are viewed as loud but less talkative (Briton and Hall, 1995). For nonverbal communication, women were perceived to have significantly better decoding and encoding skills, and were described as fluent, skilled, and effective communicators, while men were perceived to be dysfluent, less skilled, restless and loud. Women were also regarded as gentler and sweeter, but also passive and gossipy, while the men were regarded as task-oriented and logical as well as aggressive and "noisy". Their findings were consistent with previous research on gender stereotypes, which supports the theory that gender differences in communication arise because we possess stereotypes about it (Rosenkrantz et al., 1968).

Briton and Hall concluded that women were more effective in sending nonverbal messages with a specific meaning, understanding nonverbal cues, and decoding them into emotions and feelings (Briton and Hall, 1995). From the research, it can be inferred that nonverbal communication is important to females while men see nonverbal communication as unimportant.

\section{Vasyura}

The other study performed by Vasyura researched the communication differences between men and women, the male and female perceptions of a difficult communication partner of the same or opposite gender, and multiple communication styles of both men and women. Vasyura examines how children are socialized in terms of gender and how gender stereotypes eventually grow to control and regulate one's behavior. As children become adolescents and then adults, their perceptions of gender norms are shaped by the gender-normative communication they experience. It was found that during adolescence, gender-conditioned behavior was most prominent, with boys fitting practical expression stereotypes and girls fitting the expressive emotion stereotype (Vasyura, 2008). However, to some degree, older members of society also support the same gender stereotypes, but to a less extent. 
In this study, Vasyura presented two phases, the first being a sample of 240 men and 240 women from entrylevel firefighter courses at two programs. The second phase included 260 students from one university. Test included a series of personality and introspective surveys to study the various components of communicative activity. The students' individual psychological attributes were determined via another series of tests meant to determine characteristics of their nervous system, their psychodynamic characteristics, their personality, gender characteristics, as well as socio-psychological characteristics. A final test determined each individual's perception of a difficult communication partner for both genders (Vasyura, 2008).

The results showed that women display stronger internal regulation of communicative activity compared to men, and they generally put more effort into communication and take responsibility for their actions. Women have a clearer understanding of the role communication plays in life, in both professional and personal aspects, but experience more personal difficulties in communication overall. Vasyura also notes that according to recent studies a woman is seen as unobstructive when she is compliant and willing, while men who dominate are also seen as unobstructive, showing the differences in gender ideals. Based on the above information, Vasyura states that communicative activity between two genders differs in structure and expression (Vasyura, 2008). Also, males and females both have 3 styles of communication each.

Table 1 shows a qualitative comparison of the two studies. Briton and Hall and Vasyura both concluded that women were overall more empathetic when speaking, in comparison to men, who were shown to be more instrumental and practical in their speaking styles. Although neither study claimed either speaking style was more effective or persuasive, both stated the influence of gender stereotypes on society's perspective on the difference between men's and women's speaking characteristics, showing how the cyclical nature of stereotypes -- the presence of stereotypes in our childhoods makes people adopt the behavior of the stereotypes. The more agentic form of communication practiced by men was seen as significantly more acceptable and productive than the more emotional and expressive form of communication seen in women due to old gender stereotypes. Briton and Hall focused more on nonverbal communication, describing specifically how men tend to show less expression on their faces in conversations, and also attempted to interrupt others nonverbally, whereas women appeared to be better listeners and display more emotion.

Table 1. Comparison of gender communication studies.

This table shows a comparison of two gender communication studies, including verbal and nonverbal communication, as well as a focus on the comparison of male and female attributes.

\begin{tabular}{|c|c|c|}
\hline & Briton and Hall, 1995 & Vasyura, 2008 \\
\hline Number of participants & $\begin{array}{c}\text { Phase 1 } \\
\text { (4t students }- \text { 183 women, 258 } \\
\text { men }\end{array}$ & $\begin{array}{c}\text { Phase 2 } \\
\text { 480 adults -- 240 men } \\
\end{array}$ \\
\hline Country & men \\
\hline Focus & United States & Russia \\
\hline
\end{tabular}




\begin{tabular}{|c|c|c|}
\hline Methodology & Rank 20 behavioral traits & $\begin{array}{l}\text { Take several personality and intro- } \\
\text { spective tests of their cognitive } \\
\text { characteristics, as well as each in- } \\
\text { dividual's perception of a difficult } \\
\text { communication partner for both } \\
\text { genders }\end{array}$ \\
\hline Female Attributes & $\begin{array}{c}\text { Verbal } \\
\text { Talk more } \\
\text { More emotionally expressive } \\
\underline{\text { Nonverbal }} \\
\text { Better listeners } \\
\text { Encoding and decoding skills }\end{array}$ & $\begin{array}{c}\text { Verbal } \\
\text { Stronger internal regulation of } \\
\text { communicative activity } \\
\text { Put more effort into communica- } \\
\text { tion } \\
\underline{\text { Nonverbal }} \\
\text { More relaxed in conversations }\end{array}$ \\
\hline Male Attributes & $\begin{array}{c}\text { Verbal } \\
\text { Dysfluent, loud } \\
\text { Instrumental when talking } \\
\underline{\text { Nonverbal }} \\
\text { Touching face more } \\
\text { Less expressive }\end{array}$ & $\begin{array}{c}\text { Verbal } \\
\text { Communicate more practically } \\
\text { Stricter control of emotions } \\
\text { Tended toward interruptions of } \\
\text { others } \\
\underline{\text { Nonverbal }} \\
\text { Less emotion shown }\end{array}$ \\
\hline Influence of Stereotypes & $\begin{array}{l}\text { theorized that gender differences in } \\
\text { communication arise because we } \\
\text { possess stereotypes about it; stereo- } \\
\text { types have a cyclical nature in } \\
\text { which they are repeatedly proved } \\
\text { true }\end{array}$ & $\begin{array}{l}\text { children's perceptions of gender } \\
\text { norms/ psychological gender are } \\
\text { shaped by the gender-normative } \\
\text { communication they experience -- } \\
\text { stereotypes influences the youth } \\
\text { into conforming into them }\end{array}$ \\
\hline
\end{tabular}

\section{Unconscious Gender Bias and Encoding Leadership Traits}

\section{Balkwell and Berger}

Similar to gender communication research, studies on gender perception in the workplace is very limited. The two studies selected for comparison discusses the unconscious beliefs individuals hold onto that impact workplace behavior. To begin, in 1996, Balkwell and Berger studied gender perception stating four common hypotheses in sociological research regarding face-to-face interaction in task situations: the normative-influence, the informational-influence, the weighted-averaging, and the expectation states hypotheses. The sample included selection of 88 students from Northeastern College with gender-biased or -neutral labeled tasks to follow for the first study. Then, the students were paired into dyads for the second study and had to discuss the tasks from the first study more in detail observing time speaking, speech initiations, looking while speaking, gesturing, chin thrusts, smiling, laughing, and self-touching (Balkwell and Berger, 1996). The results of the studies indicated that the most highly supported hypothesis was EST, thereby emphasizing that gender identity is formed in children from a young age. 
Balkwell and Berger specifically focus on unconscious discriminaton, which is the automatic cognitive processes that lead to stereotypically masculine, feminine, or gender-neutral task behavior (Balkwell and Berger, 1996). The study aims to understand (1) the group's awareness of the social distinctions between the members, (2) the formation of different performance expectations based on the awareness of social distinctions, (3) social control within the group from the different members based on specific behaviors, and (4) differences in participation and influence.

The expectation states hypothesis (EST) was found to be the most supported in this study, and refers to the idea that one gender believes the opposite has more informational knowledge and expertise about a particular issue or topic because of the stereotypical gender linkage to the subject. The normative-influence hypothesis suggests that someone may comply with another's opinions or ideas because the other person has a higher social standing, whereas the informational-influence suggests that someone may comply with another's opinions or ideas because the other person has particular expertise in that field (Balkwell and Berger, 1996). Finally, the weighted-average, an interpretation of the EST, hypothesizes that the impact of a person is dependent on their gender and expertise combined; however, this hypothesis has too many variables to be fully considered within this study.

\section{Scott and Brown}

Conversely, Scott and Brown discuss how inherent gender bias in stereotypical leadership behavior is encoded into individuals. After reviewing previous research on gender biases, Scott and Brown were led to believe that a leader's gender can impact the manner in which leadership behaviors are encoded. A leader is identified in two steps -- first, determining the potential leadership traits someone has, and second, determining if those traits reflect one's perception of a leader. They focused first step, also known as trait encoding and activation, in which one quickly transcribes another's behavior into identifiable traits (i.e., determined); this goes on into the second step. In this study, leadership traits are divided into two categories: agentic and communal (Scott and Brown, 2006). Agentic traits are considered "masculine" and represent the male version of emotional intelligence, logical and determined, whereas communal traits are considered "feminine" and not commonly associated with leadership.

The research includes one main study and two small studies in total. The first was conducted on a group of 139 undergraduate students for which the hypothesized states that agentic and communal personality traits lineup with stereotypically male and female attributes. Participants were shown a sentence that implied a behavior, and then a word or nonword that could imply a trait; the purpose of this was to show how strongly a behavior had been encoded into an underlying trait (Scott and Brown, 2006). The results indicated that the response time for recognizing the trait was significantly faster when the leader's gender was male and when the trait was communal. Participants had a more difficult time identifying the trait when the leader was female and the trait was agentic which could allude to the idea that women are incapable of holding such agentic traits typical of a leader. However, there was no concrete evidence to support this, therefore the researchers conducted two more similar experiments to test their theory.

The second two studies ( $2 \mathrm{a}$ and $2 \mathrm{~b}$ ) had 47 and 82 students respectively. The participants were asked to form an impression about males or females who had engaged in agentic managerial behaviors. This study found that participants on average selected agentic leadership traits in male managers as self-descriptive compared to female managers. The study ultimately found that participants were more prepared to encode agentic behaviors of prototypical leadership traits when the target was male versus female (Scott and Brown, 2006).

Table 2 compares the literature of both Balkwell and Berger as well as Scott and Brown. Both study the processes that occur that contribute to unconscious gender bias. Contextually, Balkwell and Berger focus on task situations while Scott and Brown focus more concretely on leadership traits. Both similarly conclude that leadership skills or other group tasks are viewed with a gendered lens, commonly viewed as either feminine or masculine reflecting the inherent gender bias lying within our unconscious. 
Table 2. Comparison of unconscious gender bias studies.

This table shows a comparison of two unconscious gender bias studies, with a particular focus on how men and women perceived the opposite gender from an unconscious point-of-view.

\begin{tabular}{|c|c|c|}
\hline & Balkwell and Berger, 1996 & Scott and Brown, 2006 \\
\hline The Study & $\begin{array}{c}\underline{\text { Phase } 1} \\
88 \text { introductory psychology students } \\
48 \text { people -- } 24 \text { men, } 24 \text { women }\end{array}$ & $\begin{array}{c}139 \text { undergraduate students (same for all } \\
\text { three studies) }\end{array}$ \\
\hline Country & United States & Canada \\
\hline Focus & $\begin{array}{l}\text { focus on the unconscious cognitive } \\
\text { processes forming opinions and bi- } \\
\text { ases against another person that occur } \\
\text { before one's conscious deliberations, } \\
\text { specifically pertaining to gender }\end{array}$ & $\begin{array}{l}\text { focus on preconceived notions how we de- } \\
\text { velop stereotypes about leadership behav- } \\
\text { ior involving gender bias, primarily the in- } \\
\text { herent bias that men make better leaders, } \\
\text { or ideas that disqualify or discriminate } \\
\text { against leadership traits in women }\end{array}$ \\
\hline Methodology & $\begin{array}{l}\text { Phase } 1 \\
\text { asked participants to rate their famili- } \\
\text { arity with a list of activities (ie. cook- } \\
\text { ing, teaching, automotive work) } \\
\text { Phase } 2 \\
\text { formed } 24 \text { dyads out of the } 48 \text { people } \\
\text { and asked them to discuss the activi- } \\
\text { ties in phase } 1\end{array}$ & $\begin{array}{l}\text { Study } 1 \\
\text { identified if a behavior/trait showed lead- } \\
\text { ership or not } \\
\frac{\text { Study } 2 \& 3}{\text { told to form an impression of either a male }} \\
\text { or a female expressing agentic managerial } \\
\text { behaviors }\end{array}$ \\
\hline Female Attributes & $\begin{array}{l}\text { by the expectation-states hypothesis, } \\
\text { women were expected to be better at } \\
\text { sewing and cooking, stereotypically } \\
\text { "feminine" activities }\end{array}$ & $\begin{array}{l}\text { communal traits: higher emotional intelli- } \\
\text { gence, expressiveness, etc.; not associated } \\
\text { with leadership }\end{array}$ \\
\hline Male Attributes & $\begin{array}{l}\text { similarly, men were expected to be } \\
\text { better at stereotypically "masculine" } \\
\text { activities, such as automotive works; } \\
\text { however, when confronted with an } \\
\text { activity that was equally split be- } \\
\text { tween both genders, men automati- } \\
\text { cally exhibit assume more power/sta- } \\
\text { tus actions }\end{array}$ & $\begin{array}{l}\text { agentic traits: more practical and logical } \\
\text { communication; more commonly associ- } \\
\text { ated with leadership }\end{array}$ \\
\hline
\end{tabular}




\section{Women in Senior Leadership Positions}

Although half of the workforce is now preoccupied by women, the percentage of female executives is still significantly low at 17.6\% (Seo et al., 2017). Similar research has revealed that the leadership styles between men and women are similar, and that in some cases, feminine leadership qualities are preferred and praised. Seo et al. predict that the underrepresentation of women could be a result of gendered social systems, in which women's social status is perceived to be inherently lower than men's. This study examines several theories to understand the lack of promotions of women in the workplace. The social identity theory states that individuals in a social group all behave similarly to form an identity different from other groups. The similar attraction theory states that people are more attracted to others with similar traits or values as them, such as gender. Expectation states theory holds to the idea that general characteristics are used to generate assumptions about groups and who should belong in a specific group. The threatrigidity theory states that a group in power feels threatened by a group of people rising in popularity; regarding gender, men may feel threatened by the increasing number of women in the workforce, and therefore, try to get the upper hand. The attribution theory concludes that individuals are inclined to believe success is a result of effort, ability, luck and task difficulty in which one may believe a woman's success is a result of luck or effort, not ability (Seo et al., 2017). Table 3 outlines each theory explaining the reasons behind the unfair treatment of women in the workplace. This conceptual review by Seo et al. aims to understand why women hold far fewer executive positions when compared to men.

Table 3. Gendered examples of social theories.

This table describes different theories explaining the reasoning behind the discrimination against women in the workplace.

\begin{tabular}{|c|c|c|}
\hline Theory & Definition & Gendered Example \\
\hline Social Identity Theory & $\begin{array}{l}\text { individuals in a social group behave } \\
\text { similar and form an identity separating } \\
\text { them from other groups }\end{array}$ & $\begin{array}{l}\text { men and women split into different so- } \\
\text { cial groups with preconceived notions } \\
\text { about other groups }\end{array}$ \\
\hline Similar Attraction Theory & $\begin{array}{c}\text { people are more attracted to others with } \\
\text { similar traits and views }\end{array}$ & $\begin{array}{l}\text { a strong trait attracting people would be } \\
\text { gender, so the overwhelming male pres- } \\
\text { ence in executive positions would main- } \\
\text { tain male dominance in the workplace }\end{array}$ \\
\hline Expectation States Theory & $\begin{array}{l}\text { general characteristics are used to gen- } \\
\text { erate assumptions about opposite social } \\
\text { groups to be true }\end{array}$ & $\begin{array}{l}\text { this theory shows why men or women } \\
\text { might generate stereotypes about other } \\
\text { colleagues and thereby find "excuses" } \\
\text { to keep excluding them }\end{array}$ \\
\hline Threat-Rigidity Theory & $\begin{array}{l}\text { a group in power feels threatened by a } \\
\text { group rising in power, and will take ac- } \\
\text { tion to oppress the rising group }\end{array}$ & $\begin{array}{l}\text { women have been gaining an increasing } \\
\text { presence in the workplace, potentially } \\
\text { threatening their male colleague's posi- } \\
\text { tion, leading to the rise of this theory }\end{array}$ \\
\hline Attribution Theory & $\begin{array}{l}\text { individuals are inclined to believe suc- } \\
\text { cess is a result of effort, ability, luck } \\
\text { and task difficulty }\end{array}$ & $\begin{array}{l}\text { women's successes are a result of luck } \\
\text { or effort and not their abilities, making } \\
\text { them a less likely candidate for promo- } \\
\text { tion and higher-up positions }\end{array}$ \\
\hline
\end{tabular}


To further understand the theories, tangible explanations of behavioral traits of each theory are offered through backlash, self-stereotyping, the queen bee syndrome, and the old boys' club. Backlash refers to the act of minimizing the hiring of women. Self-stereotyping refers to the idea that women themselves may perceive stereotypical viewpoints of female leaders. The queen bee syndrome is the tendency of women in senior management positions to prevent other women from rising in their ranks. The "old boys' club" mentality speaks to the idea that men will stick to their own out of familiarity but also ignorance for their female counterparts (Seo et al., 2017). Each helps to understand the theories stated above illustrating more clearly why women are underrepresented in executive positions.

\section{Workplace Harassment of Women}

\section{Reporting Harassment}

On a macro level, it is important to understand how much women are impacted by workplace harassment. Three research studies were examined to understand how women respond to harassment. Hollis administered a survey to 175 colleges and universities for female faculty and administrative staff were asked to reflect on the extent of workplace bullying in American higher education. Hollis found that workplace harassment disproportionately affects women, and that it is "couched" in power, meaning that those in power automatically assume a sense of superiority over the rest of the staff (Hollis, 2017). They control the livelihoods of the women and the rest of the employees thereby making it easier for them to conceal acts of harassment. The study emphasizes four factors: gender and likelihood of reporting, likelihood to take more sick time, likelihood to leave the department, and the likelihood of resignation. The data was collected using a 35-question instrument that asked respondents from 175 colleges and universities about their experiences pertaining to workplace bullying. The results showed that women were more likely to report the issue or resign than perform any other option, meaning that formal policies and rules need to be more heavily enforced. In leaving the department and taking sick time, only about $20 \%$ of women noted that they would take such actions in response to workplace bullying (Hollis, 2017). Additionally, women are seen to be more present in entry and middle management positions, and due to employer's tendencies towards internal promotion and women's tendencies to leave the company after experiencing workplace harassment, a cycle begins in which women are continuously prevented from rising within the company. Although workplace bullying is punishable by law, there are no formal organizational policies that aim to combat harassment including inappropriate sexual advances.

\section{Counterstereotypical Characteristics}

Leskinen et al. examines how counterstereotypical (masculine) characteristics of select women can impact the amount of gender harassment they face. Within this study, the terms gender harassment and sexual harassment, as well as workplace harassment, are clearly differentiated and articulated, with gender harassment being completely nonsexual and focused primarily on stereotypes or lack thereof. Sexist remarks and gender policing are outlined among women who deviate from the feminine stereotype and have more masculine traits, such as aggression and self-reliance (Leskinen et al, 2015).

Using an internet survey, Leskinen et al. sampled 500 women varying in race and field of work. The surveys required each woman to self-rate themselves on physical appearance, masculine-typed behaviors, workgroup gender composition, and gender harassment. From there the researchers concluded that women in the workplace are caught in a "catch-22," as professional success in many highly compensated fields required stereotypically masculine behavior and appearance, but those same attributes increased women's risk for gender harassment. Gender-counterstereotypicality, in which women practiced or exhibited typically masculine traits, generally predicted more frequent exposure to sexist remarks and gender policing. Interestingly enough, women who portrayed stereotypically less feminine traits in feminine workplaces reported more gender policing than gender-stereotypical women working in primarily masculine workplaces (Leskinen et al, 2015). Thus, the management and enactment of both female-typed and maletyped traits and behaviors in the workplace presents a series of double binds for women. 


\section{Limited Resources}

Sojo et al. focuses on a variety of workplace discrimination situations from sexual versus non-sexual, and genderbased versus non-gender-based discrimination. For the purposes of this paper, the focus shall be on non-sexual organizational workplace discrimination which Sojo et al. defines as sexist discrimination, including personal experiences of bias, devaluing, and obstruction due to gender. Gender harassment is composed of experiences of hostile and offensive attitudes shown through verbal, physical, or symbolic actions triggered based on gender (Sojo et al., 2015).

This study chooses to study such discrimination from the viewpoint of stress on women. Experiences of harassment and a sexist organizational climate directly affect women's personal resources and in the long-term their psychological state and mental well-being, leading to the same outcomes as those related to other life stressors (Sojo et al., 2015). Discrimination against women at work is often downplayed and justified as the consequence of alleged merit-based systems and processes, leading to a continuation of such practices, as they are eventually seen as tolerated and acceptable in a workplace environment due to the lack of action against them.

\section{Methods}

The CSULB library database was used to collect research articles to review. Keywords such as "women discrimination", "female discrimination", "workplace discrimination of women", "female execution positions", "gender communication", "communication differences by gender", "workplace gender communication", and "gender perception of female leaders" were used to search for articles. Articles that do not pertain to female communication traits and leadership were excluded in this study. The review of the literature is split into 4 sections. The first compares and contrasts two articles about gender communication. The second part compares and contrasts two articles about unconscious gender bias viewpoints of females fulfilling group tasks as well as managerial roles. The third part examines one conceptual review article about the lack of women in executive positions. The fourth part examines the impact of workplace harassment on women. Thereafter, a qualitative analysis is discussed to understand how each theme connects to the next for a comprehensive review of this topic.

\section{Discussion}

Beginning with gender communication, it can be said that women were viewed to possess more effective communication skills than men. Also, women viewed nonverbal communication as important while men did not concern themselves with it as much as their female counterparts. This finding is consistent with Seo et al.'s claimed that female leadership qualities are viewed similarly if not preferred compared to male leaders (Seo et al., 2017). However, the lack of women in executive leadership positions begs the question if biased attitudes are a primary factor in the unfair treatment of women in the workplace including promotions.

Regarding unconscious gender bias, both articles found that more positive leadership traits were associated with men based on preconceived beliefs about gender characteristics, not based on a woman's ability to lead. Backwell and Berger, whose study was conducted over nearly a decade prior to Scott and Brown, both produced similar outcomes which is interesting as they depict the lack of change in unconscious attitudes with over a decade between each study. Even though women have a significantly higher number of workers in comparison to the 1990s, unconscious beliefs about gender continue to persist today. It should also be noted that while the 1996 study showed stereotypical job positions about each gender, the 2006 study referred to feminine and male personality qualities rather than roles (Balkwell and Berger, 1996; Scott and Brown, 2006). However, the positions are defined by the personal qualities that are stereotypically inferred about men and women.

Regarding the social theories presented by Seo et al. from 2017, the expectation states theory was tested in Balkwell and Berger from 1996, among 106 students participated in a study about unconscious gender bias (Balkwell and Berger, 1996). At the time, Balkwell and Berger presented it as a scientific hypothesis rather than a scientific 
theory. Based on the conceptual review presented by Seo et al., it can be inferred that the expectation states hypothesis has been tested and proven accurate enough times to become a theory, which are formulated based on a set of scientific studies. Therefore, if the 1996 study could be replicated today, it may yield similar results. Other theories presented by Seo et al. are worth considering as well. In fact, the theories presented prove the many layers of cognitive processes behind the discrimination against women in the workplace. Seo et al. describe the ways in which other women and men can exhibit symptoms of the queen bee syndrome, making it difficult for women to be promoted. The "old boys' club" explains the tendency for men to congregate and create a culture more desirable to men making it difficult for women to find their place in leadership committees (Seo et al., 2017).

To add, Hollis highlights the "catch-22" that many women face. Those who have counter-stereotypical characteristics, in other words, adopt the stereotypical "male" characteristics of dominance are more subject to unfair treatment (Hollis, 2017). The social theories presented by Seo et al. and the psychological phenomenon that Hollis presents illustrate the need for firmer workplace policies. Human behavior is difficult to dictate, however, policies can help to create representation where needed to promote fair treatment of women in the workplace. However, Hollis illustrates how unfair treatment and harassment continue to be a stress factor for many women. Even though women are more likely to follow workplace guidelines and report situations of abuse more than men, the lack of enforcement can lead women to leave their jobs (Hollis, 2017). In addition, Sojo et al. depict how the tendency for corporations to promote internally means that women's possibility of entering executive positions decreases substantially (Sojo et al., 2015). Work becomes a stress factor wherein women are not given the proper resources or support to gain higher roles of responsibilities in professional places.

The issues and concerns emphasized by many of these studies showed the need for new insights into corporate culture, mainly its structures and policies. In previous decades, women were able to enact a legal ban against sexual harassment and unfair treatment based on sex. However, legality is not enough. Rather, concrete actions must be enforced to reshape corporate values and policies.

One particular limitation from this literature review was the lack of research regarding women in executive positions specifically. Additionally, the studies reviewed were not specific to one country, therefore the risk of making broad generalizations is apparent; however, a study comparing workplace discrimination against women in different countries could reveal differences or similarities in gender beliefs across cultures. Finally, the length between each study could prove to be a disadvantage. However, it can also show the progress, or, in some cases, the lack of progress regarding gender biases.

\section{Conclusion}

The systems in which we live are directed by the majority and those in power. For centuries, men have held the power dictating the culture and workplace environment of companies around the world. To ensure equal treatment of women, representation is key. Having female representation in positions of decision-making would help companies to reevaluate workplace culture with a more inclusive lens. HR policies banning such discrimination is not enough. These policies must be enforced through the retraining of workers and fair hiring and promoting practices. First and foremost, however, recognizing that sexism exists is fundamental. Nonprofit organizations and government leaders can serve as allies to promote a social climate where open communication is encouraged so that we can expose the subtleties of gender bias. Furthermore, combating stereotypical beliefs at a younger age is critical. Opinions about gender can be cyclical if the next generation fails to educate the younger generations about defining qualities of a leader. Education is key to redefining gender roles as we teach the young that women too can hold powerful positions in all sectors of society. 


\section{Acknowledgements}

I would like to thank my English teacher, Mrs. King, for her insight on my paper and being my advisor for this research paper.

\section{References}

Balkwell, J. W., \& Berger, J. (1996). Gender, Status, and Behavior in Task Situations. Social Psychology Quarterly, 59(3), 273. https://doi.org/10.2307/2787023

Briton, N. J., \& Hall, J. A. (1995). Beliefs about female and male nonverbal communication. Sex Roles, 32(1-2), 79-90. https://doi.org/10.1007/bf01544758

Crenshaw, C. (1995). The "protection" of "woman": A history of legal attitudes toward women's workplace freedom. Quarterly Journal of Speech, 81(1), 63-82. https://doi.org/10.1080/00335639509384097

Hollis, L. (2017). Evasive Actions: The gendered cycle of stress and coping for those enduring workplace bullying in American higher education. Advances in Social Sciences Research Journal, 4(7), 1. https://doi.org/10.14738/assrj.47.2993

Leskinen, E. A., Rabelo, V. C., \& Cortina, L. M. (2015). Gender stereotyping and harassment: A “catch-22" for women in the workplace. Psychology, Public Policy, and Law, 21(2), 192-204. https://doi.org/10.1037/law0000040

Scott, K. A., \& Brown, D. J. (2006). Female first, leader second? Gender bias in the encoding of leadership behavior. Organizational Behavior and Human Decision Processes, 101(2), 230-242. https://doi.org/10.1016/j.obhdp.2006.06.002

Seo, G., Huang, W., \& Han, S.-H. C. (2017). Conceptual Review of Underrepresentation of Women in Senior Leadership Positions from a Perspective of Gendered Social Status in the Workplace. Human Resource Development Review, 16(1), 35-59. https://doi.org/10.1177/1534484317690063

Sojo, V. E., Wood, R. E., \& Genat, A. E. (2015). Harmful Workplace Experiences and Women's Occupational Well-Being. Psychology of Women Quarterly, 40(1), 10-40. https://doi.org/10.1177/0361684315599346

Stamarski, C. S., \& Son Hing, L. S. (2015). Gender inequalities in the workplace: the effects of organizational structures, processes, practices, and decision makers' sexism. Frontiers in Psychology, 6, 1.

https://doi.org/10.3389/fpsyg.2015.01400

Vasyura, S. A. (2008). Psychology of Male and Female Communicative Activity. The Spanish Journal of Psychology, 11(1), 289-300. https://doi.org/10.1017/s1138741600004327 